\title{
Early-Onset Isolated Bilateral Pheochromocytoma As a Major Clinical Manifestation of von-Hippel Lindau Syndrome Type $2 \mathrm{C}$
}

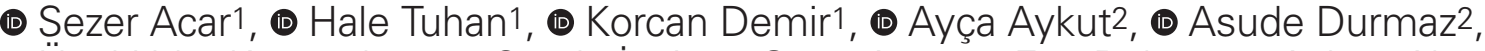 \\ (1) UUnal Utku Karaarslan3, (1) Gözde Inci4, (1) Oğuz Ateş5 (1) Ece Böber1, (1) Ayhan Abacı \\ ${ }^{1}$ Dokuz Eylül University Faculty of Medicine, Department of Pediatrics, Division of Pediatric Endocrinology, Izmir, Turkey \\ 2Ege University Faculty of Medicine, Department of Medical Genetics, Izmir, Turkey \\ ${ }^{3}$ Dokuz Eylül University Faculty of Medicine, Department of Pediatrics, Division of Pediatric Intensive Care Unit, Izmir, Turkey \\ ${ }^{4}$ Dokuz Eylül University Faculty of Medicine, Department of Pediatrics, Izmir, Turkey \\ ${ }^{5}$ Dokuz Eylül University Faculty of Medicine, Department of Pediatric Surgery, Izmir, Turkey
}

\begin{abstract}
Pheochromocytoma is a rare disease that is characterized by the increased production and secretion of catecholamines from the adrenal medulla. The disease is autosomal dominant, and frequently sporadic and unilateral. Pheochromocytoma, which is diagnosed during childhood, mostly arises as a part of cancer susceptibility syndromes. Among these syndromes, von-Hippel Lindau (VHL) syndrome is dominantly inherited, and is frequently identified in childhood pheochromocytoma. VHL syndrome is clinically characterized with hemangioblastomas of the central nervous system and retina, renal cell carcinoma, and pheochromocytoma, and has been demonstrated to have a strong genotype-phenotype correlation. In this case report, we presented an 11-year-old male who was found to have early-onset isolated bilateral pheochromocytoma and V84L mutation in VHL. We aimed to emphasize that this rarely reported mutation is associated with VHL Type $2 \mathrm{C}$ that classically manifests with early-onset isolated bilateral pheochromocytoma.
\end{abstract}

Keywords: Pheochromocytoma, von-Hippel Lindau syndrome, hemangioblastoma

\section{Introduction}

Pheochromocytoma is a rare neoplasm arising from chromaffin cells in the adrenal medulla and is characterized by increased catecholamine synthesis and release. The typical clinical manifestations are headache, excessive sweating (diaphoresis), palpitation, fatigue, and weight loss. The most important physical examination finding is hypertension, which is paroxysmal in half of the cases during childhood (1). Although pheochromocytoma can occur at any age, it most frequently emerges during the $4^{\text {th }}$ and $5^{\text {th }}$ decade of life (2). Moreover, $20 \%$ of these cases are detected in childhood and the mean age at diagnosis is 11.0 years (3). The disease is frequently sporadic and unilateral, $10 \%$ is bilateral and $10 \%$ familial (4). Pheochromocytoma can be seen as a component of cancer susceptibility syndromes such as multiple endocrine neoplasia (MEN) Types 2A and 2B (RET mutation), von-Hippel Lindau syndrome (VHL mutation), neurofibromatosis Type 1 (NF1 mutation) and Familial Paraganglioma syndromes (SDHA, SDHB, SDHC, SDHD mutations) $(5,6)$. Moreover, in most of the pheochromocytoma cases younger than 18 years of age, it has been reported to have genetic mutations in one of these tumor susceptibility genes (2). Therefore, in contrast to the adult cases, it is noteworthy to screen for genetic causes in cases diagnosed with pheochromocytoma, especially during childhood $(2,6)$. Von- 
Hippel Lindau (VHL) syndrome is a rare autosomal dominant disease and is characterized by the presence of benign and/ or malign tumors in various tissues and organs such as the central nervous system and retinal hemangioblastoma, pheochromocytoma, renal cyst, and renal cell carcinoma $(6,7)$. The association between $\mathrm{VHL}$ and pheochromocytoma was first described in 1964 (7). The incidence of VHL syndrome is estimated to be 1 in 36.000 live births (1). Pheochromocytoma was reported to occur in $20-30 \%$ of cases with VHL syndrome, and moreover, $40 \%$ of these cases were reported to have bilateral pheochromocytoma (7). A well-defined genotype-phenotype correlation between specific VHL mutations and clinical presentation has been established (6). Furthermore, VHL syndrome is classified into two groups according to the absence (Type 1) and presence (Type 2) of pheochromocytoma (6). Type 2 is also divided into 3 subgroups, and that isolated unilateral or bilateral pheochromocytoma with missense mutations in the VHL is classified as VHL Type $2 \mathrm{C}$ (6). In this case report, we aimed to present a case of $\mathrm{VHL}$ Type $2 \mathrm{C}$ who presented with isolated bilateral pheochromocytoma and who was identified through a sporadic missense mutation in the VHL.

\section{Case Report}

An 11-year-old boy was admitted to our clinic due to headache, fatigue, double vision (diplopia), night sweats, palpitation, and redness or flushing of the skin around the cheeks. He was born via normal spontaneous vaginal delivery at term with a weight of $3600 \mathrm{gr}$. It was learned from his medical history that he had undergone acute appendicitis surgery four years before. His healthy parents were not related, and family history was not remarkable. On his physical examination, his weight was $27.1 \mathrm{~kg}$ [(-1.7 standard deviation score (SDS)], height $135 \mathrm{~cm}(-1.2 \mathrm{SDS})$, body mass index was $14.1 \mathrm{~kg} / \mathrm{m}^{2}$ (-1.2 SDS). His blood pressure was $182 / 125 \mathrm{mmHg}\left(95^{\text {th }}\right.$ percentile $118 / 78 \mathrm{mmHg}$, $99^{\text {th }}$ percentile 125/86 $\mathrm{mmHg}$ ), and heart rate $119 / \mathrm{min}$. There was no hypo-hyperpigmentation, facial dysmorphology or any extremity anomalies. The testis volume was bilaterally $4 \mathrm{~mL}$, and there was no pubic or axillary hair. Laboratory analyses revealed normal liver-kidney function tests, ion profiles, and thyroid function tests. Bilateral papillary edema was detected by the ophthalmologist. Abdominal ultrasonography (USG) showed a $3 \times 3 \mathrm{~cm}$ hypoechoic mass on the right adrenal gland, and normal left adrenal gland. Abdominal magnetic resonance imaging (MRI) revealed a $4 \mathrm{~cm}$ solid mass on the right adrenal gland and a $2 \mathrm{~cm}$ solid mass on the left adrenal gland. Positron emission tomography imaging with a somatostatin analogue of gallium-68 labeled somatostatin [DOTA-D-Phe-Tyr3-octreotide (DOTATATE)] demonstrated no other pathologic uptake except bilateral adrenal masses. Epinephrine, norepinephrine, and normetanephrine levels in the serum, and normetanephrine levels in 24 hour urinary excretion were found to be high (Table I). Thyroid USG and renovascular doppler USG were normal, echocardiographic examination revealed mild left ventricular hypertrophy. Cranial and spinal MRI were normal. Clinical, laboratory and radiological findings were suggestive of bilateral pheochromocytoma. In the pre-operative period, due to its not being available in our country, an attempt was made to provide phenoxybenzamine from abroad for the treatment of hypertension. Firstly, we tried to treat the patient with selective alpha-1 blocker (doxazosin $2 \mathrm{mg} /$ day) and calcium channel blocker (nifedipine $30 \mathrm{mg} /$ day). On follow-up, because of the persistence of high blood pressure, the doses of the drugs were increased to $3 \mathrm{mg} /$ day for doxazosin, $90 \mathrm{mg} /$ day for nifedipine, and phenoxybenzamine $2 \times 5 \mathrm{mg} /$ day was added. With this treatment, we successfully controlled his high blood pressure. Laparoscopic bilateral adrenalectomy was performed following appropriate preoperative preparations (fluid infusion, methylprednisolone equivalent to hydrocortisone $100 \mathrm{mg} / \mathrm{m} \mathrm{2/day} \mathrm{just} \mathrm{prior}$ to surgery). In the intraoperative period, magnesium sulphate $(50 \mathrm{mg} / \mathrm{kg}$ as loading dose and $15 \mathrm{mg} / \mathrm{kg} / \mathrm{hour}$ as maintenance dose) was administered to prevent blood pressure elevation. During the operation, the patient did not develop hypertension, and the surgery was completed without any complications. On the postoperative fourth day, hydrocortisone treatment was replaced by oral maintenance dose $\left(10 \mathrm{mg} / \mathrm{m}^{2} /\right.$ day $)$, and fludrocortisone $(0.1 \mathrm{mg} /$ day $)$ was added. Immunohistochemical (chromogranin A and synaptophysin positive) and pathologic evaluations confirmed the diagnosis of bilateral pheochromocytoma. In the genetic analysis, no mutation was detected in the RET gene. However, a heterozygous V84L (c.250G>T, V84L) mutation in the VHL gene, which was previously reported in four families, was identified. Genetic analyses of the mother, father and the brother revealed no VHL mutation. In the further investigations regarding benign or malign tumors associated with VHL syndrome, no hemangioblastomas of the central

\begin{tabular}{|c|c|c|c|}
\hline & Parameter (unit) & Value & $\begin{array}{l}\text { Normal } \\
\text { range }\end{array}$ \\
\hline \multirow{4}{*}{ Serum } & Metanephrine (nmol/L) & 0.13 & $0.08-0.51$ \\
\hline & Normetanephrine $(\mathrm{nmol} / \mathrm{L})$ & 19.78 & $0.12-1.18$ \\
\hline & Epinephrine (pg/mL) & 109.5 & $0-60$ \\
\hline & Norepinephrine $(\mathrm{pg} / \mathrm{mL})$ & $>14000$ & $120-680$ \\
\hline \multirow{7}{*}{ Urine } & Creatinine (g/day) & 0.68 & $0.30-0.80$ \\
\hline & Metanephrine (g/day) & 157.3 & $59-188$ \\
\hline & $\begin{array}{l}\text { Metanephrine / Creatinine ratio } \\
\text { (g/g creatinine) }\end{array}$ & 232.3 & $41-209$ \\
\hline & Normetanephrine (g/day) & 10862.2 & $84-422$ \\
\hline & $\begin{array}{l}\text { Normetanephrine / Creatinine ratio }(\mu \mathrm{g} / \mathrm{g} \\
\text { creatinine) }\end{array}$ & 16038.6 & $53-413$ \\
\hline & Vanillylmandelic acid (mg/day) & 218.8 & $1.8-6.7$ \\
\hline & 5-hydroxyindoleacetic acid (mg/day) & 3.82 & $0.5-8.2$ \\
\hline
\end{tabular}


nervous system or retina, cystic or solid structures in the liver, pancreas, and kidney were detected.

Consent form was obtained from the parents of the patient for this case presentation.

\section{Discussion}

The typical symptoms (headache, palpitations, sweating), elevation of serum and urine catecholamines and their metabolites, hypertension, solid masses detected in both adrenal glands suggested the diagnosis of pheochromocytoma. Bilateral pheochromocytoma was confirmed by immunohistochemical and histological evaluations performed after surgery. Bilateral pheochromocytoma in childhood can occur as part of familial tumor syndromes such as MEN 2A/2B, neurofibromatosis Type 1, familial paraganglioma syndromes, and VHL syndrome $(2,6,8)$. In a study conducted by Baush et al. (2), genetic analyses of 177 pheochromocytoma cases, who were within the range of 4-17 years and $19 \%$ of whom were sporadic and $33 \%$ were bilateral pheochromocytoma, were performed. Various mutations regarding Familial Tumor syndromes associated with pheochromocytoma in 130 patients (80\%) were reported. Furthermore, 93 of 130 (53\%) were $V H L$ mutation as the most frequent genetic type. Of these cases with VHL mutations, 36 cases (39\%) were reported as having bilateral pheochromocytoma. In another study, Neuman et al. (5) performed genetic analyses (VHL, RET, SDHD, SDHB) of 271 pheochromocytoma cases without family history and syndromic features, and detected various genetic mutations in 66 cases (24\%). Among the cases in which mutations were detected, the most common genetic type was VHL (30 cases, 45\%). Moreover, 20 cases (66.7\%) diagnosed with VHL mutation were under 18 years of age. In the same study, it was emphasized that VHL mutations were more frequent especially in children and adolescents with isolated pheochromocytoma. Therefore, genetic causes should be investigated in cases of sporadic pheochromocytoma diagnosed in childhood. In our patient, who had bilateral pheochromocytoma at an early age, genetic studies regarding Familial Tumor Susceptibility syndromes were performed, and a de novo missense mutation (c.250G > T, V84L) was detected in the VHL gene, which was previously described in four families. There are two different subtypes of VHL syndrome (Table II). VHL Type 1 is characterized by tumor structures such as central nervous system or retinal hemangioblastoma, but no pheochromocytoma. VHL type 2 is divided into three subgroups, and unlike VHL Type 1, is accompanied by pheochromocytoma. In Type 2B, different from Type 2A, renal cell carcinoma frequently occurs. Type $2 \mathrm{C}$ is mostly presented with isolated unilateral or bilateral pheochromocytoma $(6,8)$. In some studies, the genotypephenotype correlation of the subtypes of $\mathrm{VHL}$ syndrome has been tried to be established $(8,9)$. While missense mutations are frequently detected in VHL Type 2, missense and nonsense mutations are more frequent in VHL Type 1 (9) (Table II). A missense VHL mutation (c.250G $>$ T) was

\begin{tabular}{|l|l|l|l|l|l|}
\hline \multicolumn{6}{|l|}{$\begin{array}{l}\text { Table II. Von-Hippel Lindau syndrome subtypes and genotype- } \\
\text { phenotype correlation }\end{array}$} \\
\hline $\begin{array}{l}\text { VHL } \\
\text { type }\end{array}$ & VHL mutation type & $\begin{array}{l}\text { Retinal } \\
\text { HB }\end{array}$ & CNS HB & RCC & PCC \\
\hline 1 & $\begin{array}{l}\text { Missense, insertion, } \\
\text { splice site, } \\
\text { nonsense, } \\
\text { microdeletion, wide } \\
\text { deletion }\end{array}$ & + & + & + & - \\
\hline 2A & Missense & + & + & - & + \\
\hline 2B & Missense & + & + & + & + \\
\hline 2C & Missense & - & - & - & + \\
\hline
\end{tabular}

VHL: Von-Hippel Lindau, HB: Hemangioblastoma, CNS: Central nervous system, RCC: Renal cell carcinoma, PCC: Pheochromocytoma

detected in our patient presented with isolated bilateral pheochromocytoma. As a result of this mutation, valine amino acid at position 84 was replaced with leucine. The VHL mutation (c.250G $>T$, V84L), which we identified in our case, was previously reported in 4 families (8 cases) and associated with isolated bilateral pheochromocytoma $(6,10)$. All of these cases were reported to develop isolated bilateral pheochromocytoma between the ages of 4 and 23 but on follow-up, in one of these cases, a spinal hemangioblastoma was detected at the age of 54 . However, the relationship between the spinal hemangioblastoma that developed 23 years later and VHL syndrome has not been clearly elucidated and it has been suggested that it may be coincidental. In our case, cranio-spinal imaging and retinal evaluation were normal. Taken together, the clinical and genetic results of our patient indicated the diagnosis of $\mathrm{VHL}$ Type 2C. Although neoplasia is not expected in VHL Type $2 \mathrm{C}$ except for pheochromocytoma, we planned to perform radiological screenings at regular intervals, since a case has been reported to develop spinal hemangioblastoma 21 years after bilateral pheochromocytoma was first detected. It is suggested to start preparations for surgical procedure rapidly after confirming the diagnosis of pheochromocytoma. Medical treatment should be given for at least 10-14 days prior to surgery to restore normal high blood pressure, which is caused by catecholamines (11). There are different treatment approaches for hypertension in pheochromocytoma. The most common approach in the world is to start treatment with alpha-receptor blockers (11). However, if hypertension cannot be controlled, beta-receptor blocker, calcium channel blocker should be considered (11). We first started our treatment with doxazosin, an alpha blocker. The blood pressure could not be normalized with this treatment, so we added nifedipine, a calcium channel blocker, and phenoxybenzamine, as a result of which we managed to control the hypertension. In conclusion, VHL syndrome should be considered in the differential diagnosis of childhood sporadic pheochromocytoma. It is important 
to investigate the pheochromocytoma cases diagnosed in childhood regarding genetic causes of tumor susceptibility to be able to ensure a more accurate follow-up of the patient, and to give appropriate genetic counseling.

\section{Ethics}

Informed Consent: Consent form was obtained from the parents of the patient for this case presentation.

Peer-review: External and internal peer-reviewed.

\section{Authorship Contributions}

Surgical and Medical Practices: O. A., K.D., A.A., Concept: S.A., A.A., K.D., Design: U.K., E.B., H.T., Genetic Analysis: A.A., A.D., Data Collection or Processing: G.l., S.A., A.P., Analysis or Interpretation: E.B., O.A., A.A., A.A., Literature Search: G.I., H.T., A.P., A.D., Writing: S.A., A.A., K.D.

Conflict of Interest: No conflict of interest was declared by the authors.

Financial Disclosure: The authors declared that this study received no financial support.

\section{References}

1. Lenders JW, Eisonhofer G, Mannelli M, Pacak K. Phaeochromocytoma. Lancet 2005;7:665-75.

2. Bausch $B$, Wellner $U$, Bausch $D$, et al. Long-term prognosis of patients with pediatric pheochromocytoma. Endocr Relat Cancer 2014;21:17-25.

3. Miller WL, Achermann JC, Fluck CE. Pheochromocytoma and multiple endocrine neoplasia syndromes. In: Sperling
MA (ed). Pediatric Endocrinology. 3th ed. Philadelphia, WB Saunders Elsevier, 2008;534-42.

4. Luchetti A, Walsh D, Rodger F, et al. Profiling of somatic mutations in pheochromocytoma and paraganglioma by targeted next generation sequencing analysis. Int J Endocrinol 2015;138573.

5. Neuman HP, Bausch B, McWhinneys SR, et al. Germ-line mutations in nonsyndromic pheochromocytoma. N Eng J Med 2002;346:1459-66.

6. Abbot MA, Nathanson KL, Nightingale S, Maher ER, Greenstein RM. The von-Hippel Lindau (VHL) germline mutation V84L manifests as early-onset bilateral pheocromocytoma. Am J Med Genet 2006;140:685-90.

7. Opocher G, Conton P, Schiavi F, Macino B, Mantero F. Pheochromocytoma in von Hippel-Lindau disease and neurofibromatosis type 1. Fam Cancer 2005;4:13-6.

8. Schreinemakers JM, Zonnenberg BA, Höppener JW, Hes FJ, Rinkes IH, Lips CJ. A patient with bilateral pheochromocytoma as part of a Von Hippel-Lindau (VHL) syndrome type 2C. World J Surg Oncol 2007;5:112-7.

9. Gomy I, Molfetta GA, de Andrade Barreto E, et al. Clinical and molecular characterization of Brazilian families with von Hippel-Lindau disease: a need for delineating genotypephenotype correlation. Fam Cancer 2010;9:635-42.

10. Iliopoulos O, Kibel A, Gray S, Kaelin WG Jr. Tumour suppression by the human von Hippel-Lindau gene product. Nat Med 1995;1:822-6.

11. Woodrum DT, Kheterpal S. Anesthetic management of phechromocytoma. World Journal of Endocrine 2010;2:1117. 